\title{
Sociodemographic Factors and Quality of Life in Children and Adolescents under Cancer Treatment
}

\author{
Leivy Patricia González-Ramírez1, Ricardo Gómez-Martínez², Cintia Livier Luna-Flores², \\ Cecilia Colunga-Rodríguez ${ }^{2,3}$, Mercedes Gabriela Orozco-Solis ${ }^{3}$, Rosa Ortega-Cortés ${ }^{2}$ \\ ${ }^{1}$ University Center of Tonalá, University of Guadalajara, Guadalajara, Mexico \\ ${ }^{2}$ Pediatric Hospital of the National West Medical Center at the Instituto Mexicano del Seguro Social (Mexican Social Security \\ Institute, or IMSS), Guadalajara, Mexico \\ ${ }^{3}$ University Center for Health Sciences, University of Guadalajara, Guadalajara, Mexico \\ Email: leivypagora@yahoo.com.mx
}

How to cite this paper: González-Ramírez, L. P., Gómez-Martínez, R., Luna-Flores, C. L., Colunga-Rodríguez, C., Orozco-Solis, M. G., \& Ortega-Cortés, R. (2017). Sociodemographic Factors and Quality of Life in Children and Adolescents under Cancer Treatment. Psychology, 8, 563-575.

https://doi.org/10.4236/psych.2017.84036

Received: January 25, 2017

Accepted: March 25, 2017

Published: March 28, 2017

Copyright (C) 2017 by authors and Scientific Research Publishing Inc. This work is licensed under the Creative Commons Attribution International License (CC BY 4.0).

http://creativecommons.org/licenses/by/4.0/

\begin{abstract}
The evaluation of quality of life in children and adolescents with cancer has become an increasing necessity, because of the different areas of the patient's and its families lives that get affected by this disease. The aim of this research was to determine the association between quality of life and sociodemographic variables in children and adolescents with cancer and their families. We developed a transversal and analytic study that included a sample of fifty-nine patients from four to 16 years old, along with its parents. The participants answered the KINDL survey in its children, adolescents, and parents versions $(\alpha=0.77)$. The results indicated that the lower scores of quality of life were in the socioemotional areas, particularly in school. We observed an affectation to quality of life that increases with age. Additionally, differences in the perception of quality of life of the patients and parents were found. This study provides scientific evidence about the necessity to develop personalized and opportune socioemotional interventions for the pediatric oncology services.
\end{abstract}

\section{Keywords}

Quality of Life, Sociodemographic Factors, Psycho-Oncology, Pediatrics

\section{Introduction}

The survival rate of children and adolescents with cancer has increased because of the early detention and the innovation in the existing treatments (Abu-Saad Huijer, Sagherian, \& Tamim, 2013; Litzelman, Catrine, Gangnon, \& Witt, 2011; 
Pek et al., 2010). However, it has not been possible to eliminate symptoms occasioned by the disease or its treatment, which are physical (pain and nausea), psychological (sadness, preoccupations, self-esteem diminution, fear) and social (modifications in school, family and friends environment), which affects directly in the quality of life (Abu-Saad Huijer et al., 2013; Litzelman et al., 2011).

Quality of life (QOF) is a subjective concept defined as the feeling of socioemotional and physical wellbeing, including the ability to participate in everyday activities according to age (Chaudhry \& Siddiqui, 2012; Guadarrama-Guadarrama, Hernández-Navor, Veytia López, Márquez-Mendoza, \& Carrillo-Arellano, 2015). In children and adolescents with cancer, QOL develops as a personal experience, influenced by its sickness and the institutional environments in which they spend their daily life (Chaudhry \& Siddiqui, 2012). The sickness stigma and the aggressiveness of the received medical treatments are factors that affect the patients' development, generating alterations at physical and psychological levels (Cadiz, Urzua, \& Campbell, 2011). Considering this, it is necessary to understand that QOL and health are aspects strongly related, because sickness has as important impact on the individual wellbeing and its ability to function in physical, emotional and social areas in the daily life (Chaudhry \& Siddiqui, 2012).

As the World Health Organization suggested, it is important to evaluate the QOF in children and adolescents with cancer, in order to be able to intervene opportunely in areas affected by a cancer diagnosis (Vlachioti et al., 2016). It is necessary to increase the studies about the effectivity of socioemotional interventions in children and adolescents with cancer and their families (Kazak, 2005), considering that there are only few scientific papers about it (Fedele et al., 2013; Marsland et al., 2013; Mehranfar, Younesi, \& Banihashem, 2012; Wakefield et al., 2015). In our context, despite the relevance of this variable, the research about QOF in pediatric oncology is scarce (Arias-Gómez et al., 1996; Castillo-Martínez, Juárez-Villegas, Palomo-Colli, Medina-Sansón, \& Zapata-Tarrés, 2009) increasing the exiting challenges.

Several research have identified some variables that influence the QOL of children and adolescents with cancer, such as age, gender, diagnosis and type of treatment, referring that the first six months after the diagnosis represent a period of major affectations (Vlachioti et al., 2016). Despite the impact that a cancer diagnosis can have for a pediatric patient, it is difficult to develop research with this population, because they are young and feel physically sick, not wanting to participate in studies, conditioning the information gathering to other sources, such as the parents (Llantá-AbreuI, Grau-AbaloII, \& VeaIII, 2014). However, QOL is subjective, and although the indirect information gathering is common, it is only complementary to the children or adolescent perspective (Vélez \& García García, 2012), and sometimes even contradictory (Abu-Saad Huijer et al., 2013; Chaudhry \& Siddiqui, 2012).

This research aimed to determine the association among quality of life and age, gender and school level variables in a children and adolescents with cancer and their families, looking to contribute to the existing knowledge about quality 
of life conditions of children and adolescents with cancer in Mexico.

\section{Research Settings}

The Instituto Mexicano del Seguro Social (Mexican Social Security Institute, or IMSS), is one of the main public institutions in Mexico in charge of providing medical attention at a primary, secondary and tertiary levels. The medical services are provided to adults working in the formal economy and their families.

This research was conduct in the Pediatric Hospital of the National West Medical Center. The facility provides third level medical services to the pediatric population of eleven states of western Mexico. In the oncology department, the hospital offers medical consults and treatments to children and adolescents, having external patients and others admitted to the hospital.

\section{Methodology}

\subsection{Participants}

We included 59 children and adolescents with cancer diagnosis, whose ages were between 4 and 16 years old. In addition, the patients' parents also participated in the research in order to be able to stablish comparisons between their perceptions. The pediatric participants were receiving oncological treatment at a public hospital in Mexico. We selected the participants with a convenience sampling, using a consecutive case series for the recruitment of the children and adolescents. The pediatric patients in a control stage were excluded, considering their treatment has finished.

\subsection{Instruments}

A data collection page was developed to gather information about the patient gender, age, age of diagnosis and school level. The oncological patients and its parents answered the KINDL questionnaire, developed in Germany for the evaluation of QOL in children and adolescents, for general population and hospital settings. The children from 4 to 7 years answered the Kiddy-KINDL, the group from 8 to 12 the Kid-KINDL and the adolescents from 13 to 16 the KiddoKINDL. All the adaptations have 24 questions. The parents answered specific versions accordingly to the child age, the first from 4 to 7 years old and the second from 8 to 16, both with 24 questions. All the different versions and adaptations have six dimensions: physical wellbeing, emotional wellbeing, self-esteem, family, friends and school. The answer options are in Likert scale (never, sometimes and many times for the Kiddy-Kindl; and seldom, sometimes, often and all the time in the Kid-Kindl, Kiddo-Kindl and the parents version). The questionnaires instruct the participants to think about the last seven days when answering the questions. The scores obtained from the means of each dimension were transformed in a 0 to 100 scale. The higher scores reflect a higher QOL. The global score of QOL was obtained from the dimensions total scores (Rajmila et al., 2004). The Cronbach's alpha for this questionnaire is 0.87 for the original 
version and 0.77 for Mexican population (Guadarrama-Guadarrama et al., 2015).

\subsection{Procedure}

The different KINDL adaptations and versions were apply to the participant in an interview format. When the patient and its parents arrived to the medical consult, we explained the research aims to the parents and invited them to participate. If the parent agreed, a consent form was provided, explained and signed. If the child or adolescent agreed to participate, the parent was send to a different office to answer the questionnaire, while the minor answered its own version separately. A resident physician, previously trained in the questionnaire application, conducted the interviews. The participants, minors and their parents needed an average of 20 minutes to answer the measurement instrument.

\subsection{Data Analysis}

We used the SPSS, version 20.0, program for the data capture, coding and interpretation. Initially, the results from the KNDL were interpreted in a 0 to 100 scale for each dimension and for the global QOL index. Taking into consideration the scores, we created two ordinal variables for each dimension. The first called "classification" categorized the answers as low QOL $(\leq 50)$, medium (from 51 to 75$)$ and high (>75). For the second variable "score mean", we obtained the mean of each dimension and created the variable, which included two categories "lower or equal to mean" and "higher than mean".

After this, the statistical analysis about QOL was conduct in two ways. First, we grouped the instruments and made a global comparison. Second, the same analysis was executed by age group ( 4 to 7,8 to 12 and 13 to 16 years); accordingly to the measurement instrument design (Kiddy, Kid o Kiddo).

Frequencies, average, means and standard deviation (SD) were calculated for the sociodemographic and clinic data. Later, we calculated means and SD for each KINDL dimension and global index, in order to determine its level in this population. The Kruskal Wallis test was applied to determine the mean differences by age group.

We calculated the differences in the QOL scores controlling for gender with Mann Whitney U test, for school level with Kruskal Wallis and for age with Spearman coefficient. The differences in the developed variables "Classification" and "score mean" were calculated controlling by gender and school level with Chi square $\left(\chi^{2}\right)$ and Mann Whitney $U$ for age. The parents and children differences in QOL evaluation were determined with Wilcox test. For all tests, a $p \leq$ 0.05 was considered as statistically significant.

\subsection{Ethical Considerations}

The hospital committee of ethical research reviewed and approved this research, with the R-2014-1302-35 registration number. The parents or guardian signed an inform consent letter, in which they received the information relating this study and accepted to participate in behalf of their children. 


\section{Results}

The sample included fifty-nine cancer patients from 4 to 16 years old. The sociodemographic and clinic characteristics are describe in Table 1 . The parents included in the sample were twenty-six mothers (63.4\%), ten fathers $(24.4 \%)$ and five other relatives (12.2\%). From the parent sample, eighteen were parents or relatives of a child between 4 to 7 years old, fourteen of children from 8 to 12 and nine were parents of adolescents from 13 to 16 .

The means of the QOL dimensions and the global index are in Table 2. In the patients, we observed statistically significant differences by age group in the dimensions emotional wellbeing $(p<0.05)$, self-esteem $(p<0.05)$, family $(p<$ $0.05)$, friends $(p<0.05)$, school $(p<0.001)$ and for global index $(p<0.005)$. For parents, we identify a difference in friends dimension. The highest mean was in the school dimension, evaluated by children from the 4 to 7 group $(92 \pm 14)$ and the lowest for the same dimension, but in the adolescent group (57 \pm 19 ). The means are usually higher in the children's evaluations, excepting for the adolescent group, were the patients scored lower compared to their parents.

In the global analysis, we found statistical significant differences by gender in the self-esteem and family dimensions (categorized in the "score mean" variable) of the KINDL parent version (Table 3 ). In addition, we observed differences in school level for the school dimension in the children KINDL and for the variable "score mean" (Table 4). The main differences were between preschool and elementary, and preschool and middle school. The same differences were found between the school dimension and the QOL global index $(p<0.05)$.

Table 1. Descriptive statistics for the sociodemographic and clinical patient data.

\begin{tabular}{|c|c|c|c|c|c|c|c|c|}
\hline & \multicolumn{2}{|c|}{ Global } & \multicolumn{2}{|c|}{ Kiddy (4 - 7 years) } & \multicolumn{2}{|c|}{ Kid (8 a 12 years) } & \multicolumn{2}{|c|}{ Kiddo (13 a 16 years) } \\
\hline & N (\%) & $\mathrm{M} \pm \mathrm{SD}$ & N (\%) & $\mathrm{M} \pm \mathrm{SD}$ & N (\%) & $\mathrm{M} \pm \mathrm{SD}$ & N (\%) & $\mathrm{M} \pm \mathrm{SD}$ \\
\hline \multicolumn{9}{|l|}{ Gender } \\
\hline Female & 33 (55.9) & & $13(56.5)$ & & 13 (59.1) & & $7(50)$ & \\
\hline Male & $26(44.1)$ & & $10(43.5)$ & & $9(40.9)$ & & $7(50)$ & \\
\hline \multicolumn{9}{|l|}{ School level } \\
\hline None & $2(3.4)$ & & $2(8.7)$ & & $0(0)$ & & $0(0)$ & \\
\hline Preschool & $12(20.3)$ & & $12(52.2)$ & & $0(0)$ & & $0(0)$ & \\
\hline Elementary & $23(39)$ & & $4(17.4)$ & & $16(72.7)$ & & $3(21.4)$ & \\
\hline Middle school & 8 (13.6) & & $0(0)$ & & $0(0)$ & & $8(57.1)$ & \\
\hline No data & $14(23.7)$ & & $5(21.7)$ & & $6(27.3)$ & & $3(21.4)$ & \\
\hline \multicolumn{9}{|l|}{ Tumor location } \\
\hline Central nervous system & 21 (35.6) & & $7(30.4)$ & & $8(36.4)$ & & $6(42.9)$ & \\
\hline Other & $38(64.4)$ & & $16(69.6)$ & & 14 (63.6) & & $8(57.1)$ & \\
\hline Age (years) & & $9 \pm 4$ & & $5 \pm 1$ & & $10 \pm 2$ & & $14 \pm 1$ \\
\hline Age of diagnosis & & $5 \pm 4$ & & $3 \pm 2$ & & $4 \pm 3$ & & $10 \pm 3$ \\
\hline
\end{tabular}

Note: $\mathrm{N}(\%)=$ Frequency (percentage); $\mathrm{M}=$ mean; $\mathrm{SD}=$ standard deviation. 
Table 2. Mean of scores for KIDL dimensions and global index for patients and parents.

\begin{tabular}{|c|c|c|c|c|c|c|c|c|c|c|}
\hline \multirow{2}{*}{ Dimensions } & \multicolumn{2}{|c|}{ Global analysis } & \multicolumn{2}{|c|}{$\begin{array}{l}\text { Kiddy-KINDL } \\
\text { (4 to } 7 \text { years) }\end{array}$} & \multicolumn{2}{|c|}{$\begin{array}{l}\text { Kid-KINDL } \\
\text { (8 to } 12 \text { years) }\end{array}$} & \multicolumn{2}{|c|}{$\begin{array}{l}\text { Kiddo-KINDL } \\
\text { (13 to } 16 \text { years) }\end{array}$} & \multicolumn{2}{|c|}{$\begin{array}{c}\text { Differences by } \\
\text { age group }\end{array}$} \\
\hline & $\begin{array}{l}\text { Patients } \\
M \pm D E\end{array}$ & $\begin{array}{l}\text { Parents } \\
M \pm D E\end{array}$ & $\begin{array}{l}\text { Patients } \\
\mathrm{M} \pm \mathrm{DE}\end{array}$ & $\begin{array}{l}\text { Parents } \\
M \pm D E\end{array}$ & $\begin{array}{l}\text { Patients } \\
M \pm D E\end{array}$ & $\begin{array}{l}\text { Parents } \\
\mathrm{M} \pm \mathrm{DE}\end{array}$ & $\begin{array}{l}\text { Patients } \\
M \pm D E\end{array}$ & $\begin{array}{l}\text { Parents } \\
\mathrm{M} \pm \mathrm{DE}\end{array}$ & $\begin{array}{c}\text { Patients } \\
\quad p\end{array}$ & $\begin{array}{c}\text { Parents } \\
p\end{array}$ \\
\hline Physical wellbeing & $78 \pm 21$ & $76 \pm 21$ & $75 \pm 28$ & $73 \pm 18$ & $82 \pm 17$ & $77 \pm 17$ & $76 \pm 13$ & $78 \pm 16$ & 0.570 & 0.757 \\
\hline Emotional wellbeing & $82 \pm 16$ & $79 \pm 18$ & $86 \pm 18$ & $81 \pm 17$ & $85 \pm 14$ & $78 \pm 21$ & $74 \pm 15$ & $76 \pm 15$ & 0.041 & 0.549 \\
\hline Self-esteem & $82 \pm 20$ & $80 \pm 21$ & $88 \pm 18$ & $83 \pm 17$ & $82 \pm 18$ & $82 \pm 21$ & $71 \pm 22$ & $73 \pm 26$ & 0.013 & 0.351 \\
\hline Family & $83 \pm 16$ & $78 \pm 17$ & $88 \pm 18$ & $82 \pm 15$ & $83 \pm 14$ & $77 \pm 17$ & $75 \pm 15$ & $75 \pm 19$ & 0.021 & 0.529 \\
\hline Friends & $80 \pm 20$ & $80 \pm 18$ & $85 \pm 24$ & $88 \pm 16$ & $80 \pm 17$ & $78 \pm 18$ & $73 \pm 16$ & $71 \pm 16$ & 0.046 & 0.009 \\
\hline School & $77 \pm 21$ & $74 \pm 19$ & $92 \pm 14$ & $79 \pm 17$ & $72 \pm 15$ & $73 \pm 19$ & $57 \pm 19$ & $70 \pm 20$ & $<0.001$ & 0.387 \\
\hline QOL global index & $80 \pm 13$ & $78 \pm 14$ & $86 \pm 13$ & $81 \pm 13$ & $80 \pm 11$ & $77 \pm 16$ & $71 \pm 13$ & $74 \pm 12$ & 0.002 & 0.195 \\
\hline
\end{tabular}

Note: The scores are in a 0 to 100 scale, where the scores closer to 100 represent a better quality of life. $\mathrm{M} \pm \mathrm{SD}=\mathrm{Mean} \pm$ Standard deviation. $p=$ valor de probabilidad.

Table 3. Contingency table for gender and self-esteem and family dimensions, using the score mean for the KINDL parent version.

\begin{tabular}{lccc}
\hline & $\begin{array}{c}\text { Female } \\
\mathrm{n}(\%)\end{array}$ & $\begin{array}{c}\text { Male } \\
\mathrm{n}(\%)\end{array}$ & $p$ \\
\hline $\begin{array}{l}\text { Score mean-Self-esteem } \\
\text { Lower or equal to mean } \\
\text { Higher than mean }\end{array}$ & $8(24.2)$ & $18(69.2)$ & $\mathbf{0 . 0 0 1}$ \\
$\begin{array}{l}\text { Score mean-Family } \\
\text { Lower or equal to mean } \\
\text { Higher than mean }\end{array}$ & $\begin{array}{l} \\
8(75.8)\end{array}$ & $16(30.8)$ & $\mathbf{0 . 0 1 6}$ \\
\hline
\end{tabular}

Note: Fort the variable "score mean", a mean of each dimension was calculated, developing the categories "lower or equal to mean" and "Higher than mean". The $\chi^{2}$ was applied. n (\%) = Frequency (percentage). $p<$ 0.05 considered significant.

Table 4. Contingency table for school level and school dimensions, using the score mean for the KINDL children versions.

\begin{tabular}{lccccc}
\hline & $\begin{array}{c}\text { None } \\
\mathrm{n}(\%)\end{array}$ & $\begin{array}{c}\text { Elementary } \\
\mathrm{n}(\%)\end{array}$ & $\begin{array}{c}\text { Middle school } \\
\mathrm{n}(\%)\end{array}$ & $\begin{array}{c}\text { High school } \\
\mathrm{n}(\%)\end{array}$ & $p$ \\
\hline Score mean-School & & & & & \\
$\quad$ Lower or equal to mean & $1(50)$ & $3(25)$ & $17(74)$ & $5(71)$ & 0.025 \\
$\quad$ Higher than mean & $1(50)$ & $9(75)$ & $6(26)$ & $2(29)$ & \\
\hline
\end{tabular}

Note: Fort the variable "score mean", a mean of each dimension was calculated, developing the categories "lower or equal to mean" and "Higher than mean". The $\chi^{2}$ was applied. $n(\%)=$ Frequency (percentage). $p<$ 0.05 considered significant.

We calculated the associations for the KINDL different children versions, observing a correlation between age and the QOL dimensions emotional wellbeing $(p=0.002, \mathrm{r}=-0.389)$, self-esteem $(p=0.003, \mathrm{r}=-0.377)$, family $(p=0.003, \mathrm{r}=$ $-0.378)$, friends $(p=0.003, \mathrm{r}=-0.386)$, school $(p<0.001, \mathrm{r}=-0.636)$ and QOL 
global index $(p<0.001, \mathrm{r}=-0.475)$. In the KINDL versions for parent, we found associations between age and the dimensions Friends $(p=0.001, \mathrm{r}=-0.433)$, school $(p=0.029, \mathrm{r}=-0.285)$ and QOL global index $(p=0.015, \mathrm{r}=-0.316)$.

Comparing the parent and children QOL evaluations, we observed differences in the family dimension ( $p=0.048$ ), finding a higher mean in children's evaluation $(83 \pm 16)$ compared with the parent's version mean $(78 \pm 17)$. When we developed the analysis by age groups, different results were observed, finding individual differences by gender and in the physical wellbeing dimension $(p<0.05)$ (Table 5).

Regarding correlations, in the patients 4 to 7 years group we found significant association for age and friend dimension $(p=0.006, \mathrm{r}=-0.552)$. In the group of parents with children of this age, we observed correlations for age with school dimension ( $p=0.016, \mathrm{r}=-0.497)$ and QOL global index $(p=0.03, \mathrm{r}=-0.452)$. In the rest of the age groups, we did not found significant associations.

Finally, in the comparison between patients and parents evaluation, we observed differences for the 4 to 7 years group, in the dimensions school ( $p=$ $0.004)$ and QOL global index $(p=0.048)$. The rest age groups did not presented significant associations. The statistically significant results for global analysis and age groups controlling for gender, school level and age are presented in Table 6.

\section{Discussion}

Provide integral care to children and adolescents with cancer is an increasing necessity because of the observed increase in the pediatric patients' survival rate. Being able to attend not only the physical symptoms, but also the psychological and social alterations, will allow us to release patients and families from unnecessary suffering, influencing in its quality of life (Abu-Saad Huijer et al., 2013).

Regarding QOL and its dimensions, our results indicate that in the global analysis, the school dimension obtained the lowest scores (with a mean of $77 \pm$ 21 in the children's evaluation and $74 \pm 19$ for the parents), being considered as the most affected in children and adolescents. The American Cancer Society, has emphasized the necessity of including services that attend the socioemotional needs in pediatric oncology units, particularly focusing in provide attention to

Table 5. Mean comparisons between gender and physical wellbeing dimension by age group.

\begin{tabular}{|c|c|c|c|c|c|}
\hline \multicolumn{2}{|c|}{$\begin{array}{l}\text { Kiddy-KINDL } \\
\text { (4 to } 7 \text { years) }\end{array}$} & \multicolumn{2}{|c|}{$\begin{array}{l}\text { Kid-KINDL } \\
\text { (8 to } 12 \text { years) }\end{array}$} & \multicolumn{2}{|c|}{$\begin{array}{l}\text { Kiddo-KINDL } \\
\text { (13 to } 16 \text { years) }\end{array}$} \\
\hline $\mathrm{M} \pm \mathrm{SD}$ & $\mathrm{p}$ & $\mathrm{M} \pm \mathrm{SD}$ & $\mathrm{p}$ & $\mathrm{M} \pm \mathrm{SD}$ & $\mathrm{p}$ \\
\hline
\end{tabular}

Physical wellbeing

Gender

Female

Male

NS

NS

$83 \pm 11.6$

$69 \pm 12.2$

0.049

Note: $\mathrm{M} \pm \mathrm{SD}=$ Mean \pm Standard deviation. $p<0.05$ considered significant. NS $=$ non significant associations were found. 
Table 6. Statistically significant results by global analysis and age groups for patients and parents.

\begin{tabular}{|c|c|c|c|c|c|c|c|c|}
\hline & \multicolumn{2}{|c|}{ Global analysis } & \multicolumn{2}{|c|}{$\begin{array}{l}\text { Kiddy-KINDL } \\
\text { (4 to } 7 \text { years) }\end{array}$} & \multicolumn{2}{|c|}{$\begin{array}{l}\text { Kid-KINDL } \\
\text { (8 to } 12 \text { years) }\end{array}$} & \multicolumn{2}{|c|}{$\begin{array}{l}\text { Kiddo-KINDL } \\
\text { (13 to } 16 \text { years) }\end{array}$} \\
\hline & Patients & Parents & Patients & Parents & Patients & Parents & Patients & Parents \\
\hline Gender & NS & $\begin{array}{l}\text { Self-esteem } \\
\text { Family }\end{array}$ & NS & NS & NS & NS & $\begin{array}{l}\text { Physical } \\
\text { dimension }\end{array}$ & NS \\
\hline School level & School & NS & NS & NS & NS & NS & NS & NS \\
\hline Age & $\begin{array}{c}\text { Emotional wellbeing } \\
\text { Self-esteem } \\
\text { Family } \\
\text { Friends } \\
\text { School } \\
\text { QOL }\end{array}$ & $\begin{array}{c}\text { Friends } \\
\text { School } \\
\text { QOL }\end{array}$ & Friends & $\begin{array}{l}\text { School } \\
\text { QOL }\end{array}$ & NS & NS & NS & NS \\
\hline $\begin{array}{l}\text { Differences between the } \\
\text { evaluated dimensions }\end{array}$ & Family & & & & & & & \\
\hline
\end{tabular}

Note: $\mathrm{QOL}=$ Quality of life global index score; $\mathrm{NS}=$ No statistically significant.

those patients that require more support for the reintegration to school, besides detecting and intervening in the cognitive or academic difficulties that might appear as sequels from the cancer treatment (Deasy-Spinetta, 1993).

Conversely, family is a dimension that obtained the highest score (a mean of $83 \pm 16)$ in the children's evaluation, as well as the self-esteem dimension (80 \pm $21)$ and friends $(80 \pm 18)$ for the parent evaluation. We known that cancer is a disease that generates a great impact not only in the patient, but also in the whole family, sometime immediately and other times after a while (Cadiz, Urzua, \& Campbell, 2011). The family plays an important role for the child and adolescent adjustment to its cancer treatment, finding that family cohesion is a main resource for the management of the disease and treatment adherence (Santos, Crespo, Canavarro, \& Kazak, 2015). This justify why most of the existing interventions are designed for caregivers and relatives of children and adolescents with cancer (Fedele et al., 2013; Kazak, 2005; Marsland et al., 2013; Mehranfar et al., 2012; Wakefield et al., 2015). These efforts are not to be dismissed, considering that the parents' pressure and stress directly influence the children and adolescents' clinic characteristics and QOL (Litzelman et al., 2011). The self-esteem level is influenced by many factors, among which is the type of tumor, where other studies have found that children with hematologic malignity tend to have better self-esteem than those with solid tumors that require amputations (Pek et al., 2010). Regarding the friends dimension, we will discuss later the differences found by group of age, where the score for this dimension decreases over the time.

In the analysis performed by age group to the patients' evaluations, we found statistically significant differences for almost every dimension, excepting physical wellbeing, finding that adolescents tend to have lower QOL that the younger groups. These results differ from other research that reported that adolescents have better QOL, mainly in the physical, psychological and future perspective 
dimensions, while children only scored better in physical symptoms, where apparently are less affected by the disease symptoms than the adolescents, especially in pain (Vlachioti et al., 2016). Other study found results similar to our research findings, observing a greater affectation of QOL in adolescents, particularly in physical functionality (Smith et al., 2013). The adolescents with cancer tend to present greater anger, frustration, emotional agitation and depression, according to other authors, symptoms related to the self-image alterations generated after the diagnosis. However, even when children appear to be more emotionally stable, tend to present uncertainty and confusion feelings because they did not understand its condition, observing that children not always describe they real feelings about the disease (Chaudhry \& Siddiqui, 2012). All these considerations emphasize the necessity for effective socioemotional interventions, designed by age group.

For the parents, when we compared the mean scores by age group, only differences in the friends dimension appeared. It has been observe that some parents with high stress levels tend to hide its children's cancer diagnosis to persons outside the family (Masa'Deh, Collier, Hall, \& Alhalaiqa, 2013). It is important to develop future research that can provide information about the parents' motivation to act in a specific way against this disease, being important to know the implications that social support and adjustment can have for children and parents.

In addition, we observed some differences by gender in the global analysis, for the parents in the self-esteem and family dimensions, and for the patients, in the 13 to 16 year group, in the physical wellbeing dimension. In all the dimensions, the male presented lower scores, which represent lower QOL. Other studies have found differences by gender in the reverse direction, observing that males presented better QOL in dimensions such as physical and cognitive functions, while the females reported better QOL in the social function dimension. This same study points out that, females present higher level of depression because of the greater influence that physical changes have in them (Vlachioti et al., 2016).

Regarding the differences by school level, our results showed differences in the global analysis for the school dimension, where the patients evaluated QOL less favorable as the school level increased. This situation could be originated by the cognitive alterations remaining after some cancer treatments, or even because of some psychological or emotional sequels generated after the experience of the disease (Deasy-Spinetta, 1993). Evidencing the need to develop effective socioemotional interventions that approach the patient's school life.

The age variable presented diverse statistically significant differences. For the children and adolescents evaluations, in the global analysis, all the dimensions, excepting physical wellbeing and QOL global index presented differences. For the parents, the friends and school dimension, as well as the QOL global index. In the analysis developed by age group, only the 4 to 7 years group presented differences in the friends dimension, evaluated by patients, and in the school dimension and global index, when evaluated by the parents. In all cases, we ob- 
served an inverse interaction between QOL and age.

It is necessary to mention that information about the type of tumor and age of diagnosis of the patients was obtained. However, that information will be report separately, in order to emphasize clinical aspects relevant to the findings observed in those variables and QOL.

Other important finding is the differences observed between the patients and its parent's perception of QOL. The children from 4 to 12 score higher in QOL compare to the parent evaluation, nevertheless, this results reverse for the 13 to 16 adolescents, where the patients refer a worse QOL perception than its parents. The main statistical differences found between patients and parents were in the family dimension at the global QOL analysis. Previous research have found discrepancies in the perception of QOL when is evaluated by patients and its parents (Abu-Saad Huijer et al., 2013). It has been recommended to have this bias into account when evaluations about children and adolescents QOL are performed in its parents. While it is thru that the parents evaluation can provide complementary information, it should not substitute the patient's own QOL evaluation, considering that the parents perception can be alter because of multiple factors such as the child's health state, emotional state or expectations (Vélez \& García García, 2012).

By last, it is important to highlight that, excepting the difference found in the physical dimension in 13 to 16 years adolescents, that when the QOL is evaluated in this population, the socioemotional dimensions presents more alterations. Abu-Saad Huijer and its collaborators (2013) have pointed out that the low scores found in these areas, could be due to the poor attention provided to psychological symptoms in hospital settings. Finding that supports our central idea that it is necessary to provide integral attention to children and adolescents with cancer, including socioemotional interventions for them and their family. There is some evidence of different socioemotional strategies than can be implemented in onco-pediatric services (Fedele et al., 2013; Kazak, 2005; Marsland et al., 2013; Mehranfar et al., 2012; Wakefield et al., 2015). Unfortunately, there is even more evidence of the need of effective socioemotional attention in this services (Abu-Saad Huijer et al., 2013; Castillo-Martínez et al., 2009; DeasySpinetta, 1993; Litzelman et al., 2011; Pek et al., 2010), findings to which this work is added. Most of the existing interventions have been oriented to the families, leaving the patients aside; situation that poses a challenge of providing socioemotional attention to the patients, considering it could favor the adaptation and reintegration to their daily contexts.

One of the limitations of this study is that the measurement instrument used is only validated for adolescents in Mexico (Guadarrama-Guadarrama et al., 2015). In addition, the sample size could have favored to not being able to find more differences between the patients and parents evaluations, or when controlling for the sociodemographic variables. It is necessary to increase the sample size and the participants for each age group. The heterogeneity of the sample regarding the tumor type is an element that should be taken into consideration, 
because it could explain contradictory results with other research and the high scores in the self-esteem dimension. Finally, the transversal design does not allow knowing the variations of QOL through the different stages of the disease, being important to develop longitudinal studies than can provide information about that.

\section{Conclusion}

Age, gender and school level are variables related to QOL in children and adolescents with cancer. Our findings suggest that the male and older patients tend to have lower QOL. School dimension scored lower in QOL evaluation, being one of the most affected areas after the cancer diagnosis for our patients' sample. Agreeing with the existing scientific evidence, we found differences in the QOL evaluations performed by patients and their parents, reflecting differences in the perception of the conditions faced by the participants. Even when the QOL evaluations performed by parents or guardians provide important information, they do not reflect directly the patients' QOL perceptions, so, it should not be substitute.

Patients require a multidisciplinary attention that does not only focus in the physical symptoms that children and adolescents with cancer have, but also attends the socioemotional alterations presented according to age, gender and school level. The QOL measurements can orient us about the areas than can be more affected in each group, and plan interventions specific for the individual and family needs. Despite the parents or guarding evaluation of children QOL provide useful information, it does not reflect the QOL perceived by the patients, so, it should not be substituted by them.

\section{Acknowledgements}

To the participants and institutions that collaborated in the data collection. To the University of Guadalajara and the Consejo Nacional de Ciencia y Tecnología (National Science and Technology Council CONACyT).

\section{References}

Abu-Saad Huijer, H., Sagherian, K., \& Tamim, H. (2013). Quality of Life and Symptom Prevalence in Children with Cancer in Lebanon: The Perspective of Parents. Annals of Palliative Medicine, 2, 59-70.

Arias-Gómez, J., Hernández-Hernández, D., Benitez-Aranda, H., Villasis-Keever, M. A., Bernáldez-Ríos, R., \& Martínez-García, M. C. (1996). Un instrumento para medir la calidad de vida por medio del desempeño diario en pacientes pediátricos con leucemia. Gaceta Medica De Mexico, 132, 19-28.

Cadiz, D. V., Urzua, M. A., \& Campbell, B. M. (2011). Quality of Life in Children and Adolescents Surviving Acute Lymphoblastic Leukemia. Revista Chilena De Pediatria, 82, 113-121.

Castillo-Martínez, I. D., Juárez-Villegas, L. E., Palomo-Colli, M. A., Medina-Sansón, A., \& Zapata-Tarrés, M. (2009). Quality of Life in Children with Acute Lymphoblastic Leukemia during Induction Therapy with PedsQL Cancer Module. Boletín Médico del 
Hospital Infantil de México, 66, 410-418.

Chaudhry, Z., \& Siddiqui, S. (2012). Health Related Quality of Life Assessment in Pakistani Paediatric Cancer Patients Using PedsQL 4.0 Generic Core Scale and PedsQL Cancer Module. Health and Quality of Life Outcomes, 10, 52. https://doi.org/10.1186/1477-7525-10-52

Deasy-Spinetta, P. (1993). School Issues and the Child with Cancer. Cancer, 71, 32613264.

https://doi.org/10.1002/1097-0142(19930515)71:10+<3261::AID-CNCR2820711719>3. 0.CO;2-9

Fedele, D. A., Hullmann, S. E., Chaffin, M., Kenner, C., Fisher, M. J., Kirk, K. et al. (2013). Impact of a Parent-Based Interdisciplinary Intervention for Mothers on Adjustment in Children Newly Diagnosed with Cancer. Journal of Pediatric Psychology, 38, 531-540. https://doi.org/10.1093/jpepsy/jst010

Guadarrama-Guadarrama, R., Hernández-Navor, J. C., Veytia López, M., MárquezMendoza, O., \& Carrillo-Arellano, S. S. (2015). Reliability and Factorial Structure of Kiddo-Kindle, a Tool for Measuring the Quality of Life of Mexican Teens. REMA, 20, $1-10$.

Kazak, A. E. (2005). Evidence-Based Interventions for Survivors of Childhood Cancer and Their Families. Journal of Pediatric Psychology, 30, 29-39.

https://doi.org/10.1093/jpepsy/jsi013

Litzelman, K., Catrine, K., Gangnon, R., \& Witt, W. P. (2011). Quality of Life among Parents of Children with Cancer or Brain Tumors: The Impact of Child Characteristics and Parental Psychosocial Factors. Quality of Life Research, 20, 1261-1269. https://doi.org/10.1007/s11136-011-9854-2

Llantá-AbreuI, C., Grau-AbaloII, J., \& VeaIII, H. B. (2014). Quality of Life Relating to Health in Oncopediatrics: Towards a Reflection of the Subject. Revista Habanera de Ciencias Médicas, 13, 528-536.

Marsland, A. L., Long, K. A., Howe, C., Thompson, A. L., Tersak, J., \& Ewing, L. J. (2013). A Pilot Trial of a Stress Management Intervention for Primary Caregivers of Children Newly Diagnosed with Cancer: Preliminary Evidence That Perceived Social Support Moderates the Psychosocial Benefit of Intervention. Journal of Pediatric Psychology, 38, 449-461. https://doi.org/10.1093/jpepsy/jss173

Masa'Deh, R., Collier, J., Hall, C., \& Alhalaiqa, F. (2013). Predictors of Stress of Parents of a Child with Cancer: A Jordanian Perspective. Global Journal of Health Science, 5, 8199. https://doi.org/10.5539/gjhs.v5n6p81

Mehranfar, M., Younesi, J., \& Banihashem, A. (2012). Effectiveness of Mindfulness-Based Cognitive Therapy on Reduction of Depression and Anxiety Symptoms in Mothers of Children with Cancer. Iranian Journal of Cancer Prevention, 5, 1-9.

Pek, J. H., Chan, Y. H., Yeoh, A. E., Quah, T. C., Tan, P. L., \& Aung, L. (2010). HealthRelated Quality of Life in Children with Cancer Undergoing Treatment: A First Look at the Singapore Experience. Annals of the Academy of Medicine, Singapore, 39, 43-48.

Rajmila, L., Serra-Suttona, V., Fernandez-Lopezb, J. A., Berraa, S., Aymericha, M., Ciezac, A. et al. (2004). The Spanish Version of the German Health-Related Quality of Life Questionnaire for Children and Adolescents: The Kindl. Anales de Pediatría, 60, 514521.

Santos, S., Crespo, C., Canavarro, M. C., \& Kazak, A. E. (2015). Family Rituals and Quality of Life in Children with Cancer and Their Parents: The Role of Family Cohesion and Hope. Journal of Pediatric Psychology, 40, 664-671.

https://doi.org/10.1093/jpepsy/jsv013

Smith, A. W., Bellizzi, K. M., Keegan, T. H., Zebrack, B., Chen, V. W., Neale, A. V. et al. 
(2013). Health-Related Quality of Life of Adolescent and Young Adult Patients with Cancer in the United States: The Adolescent and Young Adult Health Outcomes and Patient Experience Study. Journal of Clinical Oncology, 31, 2136-2145.

https://doi.org/10.1200/JCO.2012.47.3173

Vélez, C. M., \& García García, H. I. (2012). Medición de la calidad de vida en niños. Iatreia, 25, 240-249.

Vlachioti, E., Matziou, V., Perdikaris, P., Mitsiou, M., Stylianou, C., Tsoumakas, K. et al. (2016). Assessment of Quality of Life of Children and Adolescents with Cancer during Their Treatment. Japanese Journal of Clinical Oncology, 46, 453-461.

https://doi.org/10.1093/jjco/hyw009

Wakefield, C. E., Sansom-Daly, U. M., McGill, B. C., McCarthy, M., Girgis, A., Grootenhuis, M. et al. (2015). Online Parent-Targeted Cognitive-Behavioural Therapy Intervention to Improve Quality of Life in Families of Young Cancer Survivors: Study Protocol for a Randomised Controlled Trial. Trials, 16, 153.

https://doi.org/10.1186/s13063-015-0681-6

Submit or recommend next manuscript to SCIRP and we will provide best service for you:

Accepting pre-submission inquiries through Email, Facebook, LinkedIn, Twitter, etc. A wide selection of journals (inclusive of 9 subjects, more than 200 journals) Providing 24-hour high-quality service User-friendly online submission system Fair and swift peer-review system Efficient typesetting and proofreading procedure Display of the result of downloads and visits, as well as the number of cited articles Maximum dissemination of your research work

Submit your manuscript at: http://papersubmission.scirp.org/ Or contact psych@scirp.org 